\title{
Steroid hormone regulation of C. elegans and Drosophila aging and life history
}

\author{
Martina Gáliková, Peter Klepsatel, Gabriele Senti, Thomas Flatt* \\ Institute of Population Genetics, Department of Biomedical Sciences, University of Veterinary Medicine Vienna, Veterinärplatz 1, A-1210 Vienna, Austria
}

Keywords:

Steroid hormones

Lipophilic hormones

Ecdysone

Dafachronic acid

Nuclear hormone receptors

Life history

Aging

Lifespan

Germline

Gonad

C. elegans

Drosophila
In the last two decades it has become clear that hormones and gene mutations in endocrine signaling pathways can exert major effects on lifespan and related life history traits in worms, flies, mice, and other organisms. While most of this research has focused on insulin/insulin-like growth factor-1 signaling, a peptide hormone pathway, recent work has shown that also lipophilic hormones play an important role in modulating lifespan and other life history traits. Here we review how steroid hormones, a particular group of lipophilic hormones, affect life history traits in the nematode worm (Caenorhabditis elegans) and the fruit fly (Drosophila melanogaster), with a particular focus on longevity. Interestingly, a comparison suggests that parallel endocrine principles might be at work in worms and flies in these species and that steroid hormones interact with the gonad to affect lifespan.

\section{Introduction}

Endocrine mechanisms coordinate development and physiology in response to environmental cues and internal signals, and this regulatory plasticity is critical for adjusting and maintaining survival and reproduction in the face of environmental change (Finch and Rose, 1995; Tatar and Yin, 2001; Flatt et al., 2005; Fielenbach and Antebi, 2008). While traditionally research in endocrine physiology has focused on the effects of hormones on growth, development, and physiology, increasing evidence suggests that hormones and mutations in genes involved in endocrine signaling can also have pervasive effects on whole organism life history traits, in particular longevity (Tatar et al., 2003; Tu et al., 2006; Toivonen and Partridge, 2009; Fielenbach and Antebi, 2008). One such central endocrine pathway, for example, the insulin/insulin-like growth factor-1 (IGF-1) signaling (IIS) pathway, has been found to be a major regulator of lifespan and other life history traits in worms, flies, and mice (Tatar et al., 2003; Giannakou and Partridge, 2007; Fielenbach and Antebi, 2008). However, while most current research is focused on understanding the details whereby this evolutionarily conserved peptide hormone

\footnotetext{
* Corresponding author. Tel.: +43 125077 4334; fax: + 431250774390. E-mail address: thomas.flatt@vetmeduni.ac.at (T. Flatt).
}

receptor pathway influences life history and aging, much less is known about the effects of other endocrine pathways.

Recent work in the roundworm (Caenorhabditis elegans) and the fruit fly (Drosophila melanogaster) has now begun to reveal that nuclear hormone receptors (NHRs) and their lipophilic ligands profoundly affect aging and related life history traits (Tatar et al., 2003; Flatt et al., 2005; Rottiers and Antebi, 2006; Tu et al., 2006; Fielenbach and Antebi, 2008; Toivonen and Partridge, 2009). Here we review the recent findings about how lipophilic steroid hormones and their receptors affect lifespan and related life history traits in $C$. elegans and D. melanogaster. Based on the available data, we argue that the steroid regulation of lifespan and associated life history traits is governed by parallel endocrine principles in worms and flies.

\section{Steroid hormones as master regulators of development and physiology}

Steroid hormones are small, fat soluble, cholesterol-derived molecules that can pass through the cell membrane into the cytoplasm where they activate signaling by binding to cytosolic or nuclear receptor proteins. Steroid hormone receptors are members of the large superfamily of nuclear hormone receptors (NHRs), a group of transcription factors that bind lipophilic hormones (e.g., steroids, retinoids, thyroid hormones, bile-acid like hormones, and fatty acids) 
and that regulate the transcription of many target genes (Gronemeyer and Laudet, 2001). By controlling transcription, NHRs coordinate many aspects of development, physiology, and metabolism (Chawla et al., 2001; Francis et al., 2003; King-Jones and Thummel, 2005; Flatt et al., 2006; Magner and Antebi, 2008).

NHRs are typically defined by a ligand-binding domain (LBD), which can also bind co-activators and co-repressors, and by an evolutionarily conserved N-terminal DNA-binding domain (DBD). Different genomes vary dramatically in the number of loci that encode NHRs: Drosophila, for example, has only 18, and humans have 48, whereas the C. elegans genome contains 248 NHRs (Gronemeyer and Laudet, 2001; Gissendanner et al., 2004; King-Jones and Thummel, 2005; Robinson-Rechavi et al., 2005). Although for many NHRs, especially those of vertebrates, ligands have been identified, many are so-called "orphan" receptors without known ligand. Furthermore, several NHRs can function without ligand (Mangelsdorf and Evans, 1995; Gronemeyer and Laudet, 2001).

Among the functionally best understood NHRs are the steroid hormone receptors DAF-12 (dauer formation 12) in C. elegans and EcR (ecdysone receptor) in Drosophila. Both receptors activate highly pleiotropic signaling pathways that regulate a multitude of developmental and physiological processes and that are crucial for coordinating life history in response to environmental and internal inputs.

\section{DAF-12 is a key coordinator of C. elegans life history}

C. elegans DAF-12, a homolog of the vertebrate vitamin D receptor (VDR) and the liver $\mathrm{X}$ receptor (LXR), plays multiple roles in regulating development and physiology in response to environmental conditions, including major effects on developmental timing, dauer formation, reproductive maturation, metabolism, and lifespan (Antebi et al., 2000; Snow and Larsen, 2000; Gerisch et al., 2001; Rottiers and Antebi, 2006; Gerisch et al., 2007). Thus, DAF-12 appears to be a hormonal master coordinator of $C$. elegans life history (Fielenbach and Antebi, 2008; Magner and Antebi, 2008).

In functional terms, DAF-12 signaling is best understood for its effects on developmental timing and reproductive maturation, especially with regard to dauer formation (Antebi et al., 2000; Gerisch et al., 2001; Rottiers and Antebi, 2006; Fielenbach and Antebi, 2008). Under benign environmental conditions $C$. elegans develops through four larval stages to a reproductive adult in 3-5 days, but in response to adverse conditions such as starvation, high temperature, or crowding worms enter an alternative third larval stage, the so-called "dauer", a non-feeding, stress-resistant diapause stage that can live up to 3-6 months. Once favorable conditions have returned, dauer larvae resume development and progress into reproductively mature adults with normal adult lifespan. Null mutations in daf-12, which typically affect the DBD, cause a "dauer formation-defective" (Daf-d) phenotype that bypasses the dauer state irrespective of environmental conditions, whereas lesions in the LBD typically induce a "dauer formation-constitutive" (Daf-c) phenotype that always enters the dauer state (Rottiers and Antebi, 2006; Fielenbach and Antebi, 2008). Certain dauer formation mutants of DA/DAF-12 can also bypass the larval dauer stage and become long-lived, stress-resistant adults (Rottiers and Antebi, 2006; Fielenbach and Antebi, 2008; see discussion later).

Although for a long time DAF-12 was an "orphan" NHR without known ligand, recent work has identified several DAF-12 ligands and begun to elucidate their biosynthesis and effects upon dauer formation and other phenotypes. Several genes that act upstream of DAF-12 are known to encode enzymes required for ligand production: the C. elegans Niemann-Pick type C1 (NPC) homologs ncr-1 and ncr-2 which are important for cholesterol trafficking and sterol homeostasis (Sym et al., 2000; Li et al., 2004; Motola et al., 2006); the cytochrome P450 (CYP450) gene daf-9 related to steroidogenic hydroxylases (Gerisch et al., 2001; Jia et al., 2002; Mak and Ruvkun, 2004); daf-36 which encodes a Rieske-like oxygenase (Rottiers et al., 2006); and hsd-1, a 3- $\beta$-hydroxysteroid dehydrogenase family member (Patel et al., 2008). These enzymes form part of a biosynthesis pathway that leads to the production of two 3-keto bile-acid like steroids, $\Delta-4$ and $\Delta-7$ dafachronic acid (DA), that specifically bind and activate DAF12 (Motola et al., 2006). Furthermore, a related bile-acid, 25Scholestenoic acid (CA), has also been found to bind DAF-12 (Held et al., 2006). Supplementation with DA rescues dauer and other phenotypes of $n c r-1, n c r-2$, daf-9, and daf-36 mutants, and application of CA rescues daf-9 mutants (Held et al., 2006; Motola et al., 2006; Rottiers et al., 2006; Gerisch et al., 2007; Sharma et al., 2009). A common vertebrate steroid, pregnenolone, might also act as a DAF-9 produced ligand of DAF-12 (Broué et al., 2007), but since pregnenolone cannot activate DAF-12 in vitro this molecule might only represent a ligand precursor (Motola et al., 2006).

DA/DAF-12 signaling interacts with several other endocrine pathways known to affect dauer formation such as cGMP, TGF- $\beta$, and IIS (Fielenbach and Antebi, 2008). Epistasis analyses position DAF-12 signaling downstream of cGMP, TGF- $\beta$, and IIS, with daf- 12 null mutations suppressing Daf-c mutant phenotypes in these pathways (Riddle et al., 1981; Vowels and Thomas, 1992; Thomas et al., 1993). For example, insulin-like peptides (ILPs) that bind to the insulin-like receptor DAF-2 are thought to be required for DAF-9/DAF36 activity and DA production (Rottiers and Antebi, 2006; Fielenbach and Antebi, 2008), and epistasis experiments place DAF-16/FOXO, a forkhead transcription factor downstream of IIS, upstream of DAF-9 and DAF-12 (Gerisch et al., 2001; Jia et al., 2002). Conversely, DA, HSD-1, DAF-9 and DAF-12 can exert feedback effects on DAF-16/FOXO activity (Matyash et al., 2004; Gerisch et al., 2007; Dumas et al., 2010), and DAF-12 and DAF-16/FOXO interact in co-immunoprecipitation assays (Dowell et al., 2003). In addition to its interactions with DAF16/FOXO, DAF-12 also interacts with DAF-2 (Gems et al., 1998; Larsen et al., 1995). The DA/DAF-12 and IIS/DAF-2/DAF-16 pathways thus intersect in multiple and complex ways (Gems et al., 1998; Fielenbach and Antebi, 2008).

The data at hand suggest a unifying model of how steroid hormones regulate $C$. elegans life history: under favorable conditions, activation of IIS and TGF- $\beta$ pathways stimulates the production of DA (and possibly other ligands) and liganded DAF-12 promotes reproductive growth and adult development, whereas unliganded DAF-12 induces a program that promotes dauer development, survival, and stress resistance (Rottiers and Antebi, 2006; Fielenbach and Antebi, 2008). Interestingly, as we will discuss next, insects such as Drosophila coordinate development, physiology, and life history by employing a steroid hormone pathway that is similar to DAF-12/DA signaling.

\section{EcR signaling orchestrates Drosophila development and physiology}

In the fruit fly and other insects, the ecdysone receptor (EcR), a homolog of the vertebrate farnesoid $\mathrm{X}$ receptor (FXR) and liver $\mathrm{X}$ receptor (LXR), mediates signaling by steroid hormones called ecdysteroids. Like DAF-12, EcR signaling coordinates development and physiology by eliciting various cell autonomous and non-autonomous transcriptional responses in many target tissues (Riddiford, 1993; Riddiford et al., 2000; Kozlova and Thummel, 2000; Thummel, 2001a; King-Jones and Thummel, 2005; Spindler et al., 2009).

The hormonally active ligand of EcR, 20-hydroxy-ecdysone (20E), is produced from a cholesterol precursor derived from dietary yeast ergosterol or plant sterols; thus, like C. elegans, Drosophila is a cholesterol auxotroph (Gilbert et al., 2002; Kurzchalia and Ward, 2003). Ecdysteroids are produced in response to prothoracicotropic hormone (PPTH) and nutritional inputs integrated and relayed by IIS (McBrayer et al., 2007; Colombani et al., 2005). The first step is the conversion of cholesterol into 7-dehydro-cholesterol (7-DHC) by a Rieske-like oxygenase encoded by neverland ( $n v d$; Yoshiyama et al., 
2006) in steroidogenic tissues (larval prothoracic gland, adult gonad), and 7-DHC is subsequently transformed by cytochrome P450 enzymes (e.g., encoded by "Halloween" genes such as phantom, disembodied, shadow) into several intermediate products. The final step is the conversion of the prehormone ecdysone (E) into 20E by an intracellular mono-oxygenase encoded by shade in peripheral tissues such as epidermis, gut, fat body (equivalent to mammalian liver and adipose tissue), and Malphigian tubules (equivalent to the kidney) (Gilbert et al., 2002; Petryk et al., 2003; Gilbert and Warren, 2005). At the target tissues, 20E activates signaling by binding to a heterodimer that consists of EcR and another NHR, ultraspiracle (USP), a homolog of vertebrate retinoid X receptor (RXR) (Koelle et al., 1991; Yao et al., 1993; King-Jones and Thummel, 2005), with well-known downstream signaling effects (Thummel, 1996; Kozlova and Thummel, 2000). However, other signaling modes of $20 \mathrm{E}$ that do not involve EcR, for example non-genomic actions, or signaling via heterodimers consisting of Drosophila hormone receptor 38 (DHR38) and USP, have been reported as well (Baker et al., 2003; Srivastava et al., 2005).

Pulses of 20E orchestrate the development from the embryo through the three larval instars into the reproductively mature adult, in particular developmental timing and metamorphosis (Riddiford, 1993; Thummel, 1996; Kozlova and Thummel, 2000; Truman, 2005). In brief, 20E regulates a wide range of developmental and cellular processes such as cell polarity (Romani et al., 2009), cell cycle (Fallon and Gerenday, 2010), and cell migration (Bai et al., 2000), as well as cell and tissue proliferation, differentiation, histolysis, and apoptosis (Thummel, 1996, 2001b). In the adult, 20E affects, among other things, courtship behavior (Ishimoto et al., 2009), vitellogenesis and egg production (Bownes, 1982; Richard et al., 1998, 2001; Buszczak et al., 1999; Carney and Bender, 2000), adult reproductive diapause (Richard et al., 2001), innate immunity (Flatt et al., 2008b), as well as stress resistance and lifespan (discussed later).

The similar nature and range of developmental, physiological, and whole organism life history traits influenced by 20E/EcR and DA/DAF12 suggests that there are striking parallels between the steroid hormone pathways of worms and flies. It is thus tempting to speculate that $20 \mathrm{E} / \mathrm{EcR}$ and DA/DAF-12 might in fact represent functionally homologous endocrine systems.

\section{Parallels between DA/DAF-12 and 20E/EcR signaling}

Several important facts lend support to the notion that DA/DAF-12 and $20 \mathrm{E} / \mathrm{EcR}$ signaling are functionally equivalent (see Fig. 1). Perhaps most importantly, as we have pointed out previously, 20E/EcR and DA/DAF-12 share many similar regulatory functions in development, physiology, and life history, in particular in terms of developmental rate and timing, reproductive maturation, and diapause-like survival states. For example, the endocrine regulation of the stress-resistant, long-lived larval dauer stage in C. elegans has been likened to that of adult reproductive diapause (dormancy) in Drosophila and other insects, a non-reproductive, stress-resistant and long-lived alternative phenotype that is elicited by low temperature and shortened photoperiod (Tatar and Yin, 2001).

Consistent with the view that 20E/EcR and DA/DAF-12 represent homologous pathways, the LBD of DAF- 12 has $34 \%$ sequence similarity to that of EcR (Antebi et al., 2000). The DAF-12 LBD is also closely related to that of Drosophila hormone receptor 96 (DHR96; 40\% similarity), a NHR that binds cholesterol and regulates cholesterol homeostasis and xenobiotic metabolism (King-Jones et al., 2006: Horner et al., 2009); however, since DAF-12 and EcR share many biological functions, EcR seems to be a more promising candidate for the DAF-12 ortholog. Parallels between DA/DAF-12 and 20E/EcR also apply to ligand production. While NCR-1 and NCR-2 are required for DA production in the worm, the Drosophila homolog of NCR-1 (NPC-1) is necessary for 20E synthesis, and npc-1 mutants can be rescued by 20E application (Huang et al., 2005, 2007; Fluegel et al.,
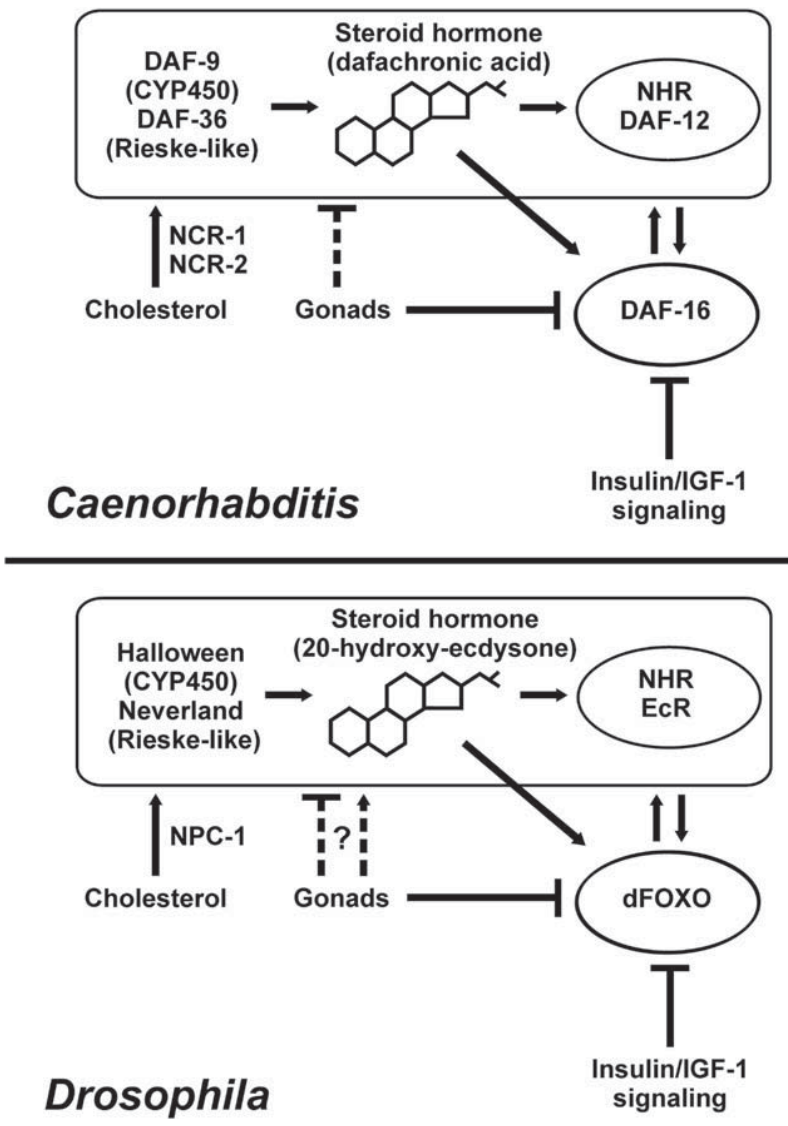

Fig. 1. Models of functional endocrine parallels in the steroid hormone regulation of life history traits, especially lifespan, between (A) C. elegans and (B) D. melanogaster. See text for details.

2006). Similarly, the Rieske-like oxygenase NVD required for $20 \mathrm{E}$ production in Drosophila represents the homolog of DAF-36 required for DA synthesis in C. elegans (Yoshiyama et al., 2006). Thus, there exist fundamental homologies between DA/DAF-12 and 20E/EcR signaling, both in terms of hormone biosynthesis and receptormediated signaling.

A comparison of worms and flies further reveals similar regulatory wiring of interactions between steroid hormone signaling and IIS. In the nematode, DAF-9/DAF-36 activity and DA production require IIS, and in Drosophila 20E production depends upon IIS as well (Tu et al., 2002; Colombani et al., 2005; Walkiewicz and Stern, 2009). For example, mutants of the Drosophila insulin receptor (dInR) exhibit decreased ecdysteroid levels (Tu et al., 2002). Similarly, decreased IIS in the prothoracic gland of the fly reduces expression of the Halloween genes disembodied and phantom and decreases $20 \mathrm{E}$ production, whereas upregulation of IIS has the opposite effect (Colombani et al., 2005). IIS is therefore required for steroid hormone production in worms and flies, as is also observed in other species, such as mosquitoes (Riehle and Brown, 1999), blowflies (Maniere et al., 2004) and mammals (L'Allemand et al., 1996). Interestingly, steroid hormones can also have feedback effects upon IIS. For example, DA/DAF-12 modulates the activity of DAF-16/FOXO in the nematode, and $20 \mathrm{E} / \mathrm{EcR}$ regulates the activity of the fly homolog of DAF-16, dFOXO (Colombani et al., 2005). The recent observations in Drosophila by Colombani et al. (2005) are particularly interesting in view of the well-known genetic interactions between DAF-12 and IIS/ DAF-2/DAF-16 in C. elegans previously mentioned further.

Taken together, the current evidence suggests that DA/DAF-12 and 20E/EcR are homologous endocrine systems. These parallels also appear to extend to the regulation of lifespan (Fig. 1). 


\section{Similarities in the steroid hormone regulation of lifespan between worms and flies}

In addition to the well-known effects on the longevity of IIS and pathways, recent experiments in C. elegans and D. melanogaster have also identified several steroid and other lipophilic hormones as important regulators of longevity, including DA in worms and 20E in flies (Tatar et al., 2003; Flatt et al., 2005; Flatt and Kawecki, 2007; Rottiers and Antebi, 2006; Tu et al., 2006; Russell and Kahn, 2007; Fielenbach and Antebi, 2008; Toivonen and Partridge, 2009).

In both worms and flies steroid hormone deficiency seems to extend lifespan. In C. elegans, strong daf-9 mutations extend adult lifespan and increase stress resistance, and this effect depends on DAF-12 and the DAF-12 co-repressor DIN-1 (Gerisch et al., 2001; Jia et al., 2002; Ludewig et al., 2004). In contrast, the hypomorphic mutant alleles of daf- 9 and daf-36 have no or only little effect upon longevity (Gerisch et al., 2001; Jia et al., 2002; Rottiers et al., 2006). Because DAF-9 is required for DA synthesis, DA deficiency might promote longevity through the unliganded DAF-12 receptor. Consistent with this model, DA supplementation suppresses the lifespan extension of DA-deficient daf-9 mutants (Gerisch et al., 2007). As in the nematode, steroid hormone deficiency also extends lifespan in Drosophila. Temperature-sensitive female mutants of DTS-3, a gene encoding a protein with Krüppel Zn-finger domains but whose molecular identity remains unknown, have a 50\% reduction in ecdysteroid titers, are infertile, and long-lived (Walker et al., 1987; Simon et al., 2003). Like the effects of DA supplementation in daf-9 mutants, 20E supplementation restores lifespan of 20E deficient DTS-3 mutants to wild-type levels (Simon et al., 2003). Similarly, 20E deficient mutants of dare, a gene encoding an adrenoxin reductase required for 20E biosynthesis (Freeman et al., 1999), are long-lived (Simon and Krantz, 2005). Thus, in both worms and flies DA and 20E promote aging, whereas hormone deficiency promotes longevity.

Striking parallels between C. elegans and Drosophila are also found when we compare the longevity effects of the steroid hormone receptors. Certain mutants of daf-12 can affect lifespan, but the magnitude and direction of the effects depend on the mutant allele and on sex (Fisher and Lithgow, 2006; McCulloch and Gems, 2007). daf-12 (rh61rh411), a putative Daf-d null allele with nonsense mutations affecting both the DBD and LBD, shortens lifespan, but daf-12 (rh273), a Daf-c mutation thought to cause ligand insensitivity, extends lifespan (Fisher and Lithgow, 2006). Sex-specific effects of DAF-12 are seen with the Daf-d mutant allele daf-12 (m20) that weakly extends lifespan in males, but shortens it in hermaphrodites (McCulloch and Gems, 2007). DAF-12 thus exhibits "janus"- or "chimera"-like behavior with regard to its effects on aging (Fisher and Lithgow, 2006; Rottiers and Antebi, 2006). A similar situation might apply to the effects of EcR on lifespan in Drosophila. Whereas several constitutive mutations in the EcR LBD and DBD have been reported to cause lifespan extension in both females and males (Simon et al., 2003), a recent study has found that mild adult-specific inactivation of EcR by RNAi increases lifespan in males, but decreases it in females (Tricoire et al., 2009). Like DAF-12 signaling, EcR might thus have context-dependent effects on aging.

The complex interactions between DA/DAF-12 and IIS provide another illustration of such "chimera"-like behavior of steroid hormone signaling in longevity. For example, while daf-12 null mutants synergistically increase the longevity of strong (class II) daf-2 (insulin-like receptor) mutants, lifespan extension of weak daf-2 mutants are suppressed by class III daf-12 mutants (Larsen et al., 1995; Gems et al., 1998). Furthermore, the increased longevity phenotype of daf-2 mutants, but not that of daf-9 mutants, requires DAF-16/FOXO and is fully suppressed by mutations in daf-16/foxo, suggesting that DAF-9 and DAF-16/FOXO function independently to affect longevity (Gerisch et al., 2001; Jia et al., 2002). However, although DA treatment is unable to suppress longevity in daf-2 mutants, it can in fact enhance the longevity of daf-2 (e1368) mutants (Gerisch et al., 2007). In some contexts, therefore, DA/DAF-12 might act to maximize IIS/DAF-2/DAF-16 dependent longevity (Gerisch et al., 2007). Whether interactions between EcR and IIS/dInR/dFOXO also affect Drosophila lifespan is currently unknown, but the fact that $20 \mathrm{E}$ is able to modulate dFOXO activity in larval flies (Colombani et al., 2005) makes this an attractive possibility.

The mechanisms underlying the janus-like behavior of DAF-12 and EcR signaling with regard to lifespan are currently unknown and await future study. For instance, it has been suggested that this signaling behavior might be due to the fact that DAF-12 can switch between an activator and repressor state that depends on the availability of corepressors or co-activators (Rottiers and Antebi, 2006). In Drosophila, EcR signaling is similarly modulated by co-activators (taiman; Bai et al., 2000) or co-repressors (SMRTER or Alien; Tsai et al., 1999; Dressel et al., 1999), and it would be interesting to examine the effects of such cofactors on lifespan regulation. Moreover, both DAF-12 and EcR have several receptor isoforms (Bender et al., 1997; Antebi et al., 2000; Mouillet et al., 2001), and it is possible that distinct isoforms might have different effects on lifespan (Snow and Larsen, 2000).

Clearly, in both C. elegans and Drosophila steroid hormones have comparable effects on lifespan, thereby further supporting the notion that DA/DAF-12 and 20E/EcR signaling are equivalent (Fig. 1). Moreover, in C. elegans - and possibly also in Drosophila - steroid hormone signaling interacts with the gonad to regulate lifespan, as we discuss below (Fig. 1).

\section{In worms and flies the longevity effects of steroid hormones depend on the gonad}

In the nematode, ablation of germline precursor cells extends lifespan by about $60 \%$, while simultaneous ablation of the somatic gonad abolishes this effect, suggesting that the germline and somatic gonad produce signals with opposing effects on longevity (Hsin and Kenyon, 1999; Yamawaki et al., 2008). The lifespan extending effect of germline ablation requires the activity of several genes involved in IIS and DA/DAF-12 signaling (Fielenbach and Antebi, 2008). In the context of IIS, germline ablation is unable to extend lifespan in mutants of daf-16/Foxo (Hsin and Kenyon, 1999). Remarkably, in the case of strong daf-2 mutants the somatic gonad is dispensable for germline ablation to extend lifespan by activating DAF-16/FOXO (Yamawaki et al., 2008). This suggests that the somatic gonad normally provides factors that suppress IIS below a critical threshold, but that these factors are no longer necessary for germline ablation to extend lifespan when the levels of IIS are sufficiently low (Yamawaki et al., 2008). With regard to DA/DAF-12 signaling, HSD-1 is dispensable for lifespan extension caused by germline ablation (Dumas et al., 2010), but germline ablation is unable to extend lifespan in daf-12 mutants (Hsin and Kenyon, 1999; Motola et al., 2006; Gerisch et al., 2007). Similarly, longevity of germline-ablated worms is also abrogated in mutants of daf-9 and daf-36, suggesting that DA/DAF-12 is required for germline ablation to promote longevity (e.g., Gerisch et al., 2001, 2007; Gerisch and Antebi, 2004; Rottiers et al., 2006). While germline ablation cannot extend lifespan in these DA-deficient mutants, longevity can be restored by application of DA (Gerisch et al., 2007). In contrast, the lifespan of daf-12 mutants and germline-ablated daf-12 mutants is not affected by DA, suggesting strict dependence of the ligand on DAF-12 function (Gerisch et al., 2007). Interestingly, both germline ablation and DA supplementation activate DAF-16/FOXO (Gerisch et al., 2007), suggesting regulatory crosstalk between DA/DAF-12 and IIS/DAF-16 (also see previous discussion, and Section 3). Interestingly, germline ablated worms have elevated pregnenolone, and application of pregnenolone to germline ablated daf-9 mutants can restore their longevity (Broué et al., 2007); however, it remains unclear whether 
pregnenolone represents a bona fide ligand of DAF-12 (Motola et al., 2006).

In the fly, we do not currently know whether germline ablation and steroid hormone signaling converge to affect lifespan, yet several lines of evidence suggest that the gonad might interact with 20E/EcR signaling to affect fly lifespan. This possibility is particularly intriguing since EcR is not only expressed in the ovary in both germline and somatic cells and required for oogenesis (Buszczak et al., 1999; Carney and Bender, 2000), but also because the gonad is the major site of ecdysteroid production (Gilbert et al., 2002). Similar to C. elegans, we have recently found that ablation of germline stem cell can extend lifespan and modulate IIS/dFOXO in Drosophila, suggesting that the gonadal regulation of aging might be evolutionarily conserved (Flatt et al., 2008a). Germline-less, long-lived flies also exhibit increased expression of the secreted fly insulin/IGF-binding protein IMP-L2 (Flatt et al., 2008a), and IMP-L2 is an IIS antagonist (Honegger et al., 2008) known to be induced by $20 \mathrm{E}$ (Natzle et al., 1986; Osterbur et al., 1988; Andres et al., 1993). It is therefore an interesting possibility that in flies germline ablation extends lifespan by interacting with IIS and $20 \mathrm{E} / \mathrm{EcR}$ signaling, as is the case in the nematode. Direct evidence for an interaction between EcR signaling and the gonad in modulating lifespan comes from a recent study by Tricoire et al. (2009): the authors found that EcR inactivation decreases female lifespan, but this effect is rescued in sterile female mutants of $o v o^{D 1}$, a mutation that causes developmental arrest of egg chambers prior to or at stage 4 (Oliver et al., 1987). Although it remains unclear whether ovo ${ }^{D 1}$ mutants have defective germline stem cell proliferation (cf. Flatt et al., 2008a), or whether they are 20E deficient (the ovary is the major $20 \mathrm{E}$ producing tissue in the female fly), this important result shows that $20 \mathrm{E} / \mathrm{EcR}$ signaling can interact with the gonad to modulate lifespan. Another interesting observation is that sterile, long-lived mutants of dInR exhibit ovarian ecdysteroid deficiency - and 20E deficiency might thus contribute to lifespan extension upon reduced IIS (Tu et al., 2002). Finally, adult Drosophila females undergoing reproductive diapause Drosophila exhibit ovarian (vitellogenic) arrest, increased stress resistance, and greatly improved adult survival (Tatar and Yin, 2001; Schmidt and Paaby, 2008), and diapause is associated with reduced ovarian ecdysteroid levels, a condition that can be rescued by 20E application (Richard et al., 1998, 2001). In addition, natural variation in diapause incidence has been mapped to the couch potato locus, a gene encoding an ecdysteroid-responsive RNA binding protein that is expressed in the peripheral nervous system and the ring gland, a composite larval endocrine organ that contains the ecdysteroidogenic prothoracic gland (Schmidt et al., 2008; P. S. Schmidt, personal communication). Thus, although the evidence from Drosophila discussed above is circumstantial, the data suggest intricate connections among the gonad, 20E/EcR, IIS, and longevity that deserve further investigation (Fig. 1).

\section{Conclusions}

The recent discoveries in the nematode and the fruit fly reviewed previously clearly suggest that DA/DAF-12 and 20E/EcR represent functionally equivalent steroid hormone pathways with similar effects on life history, in particular on longevity. Intriguingly, in both species the gonad appears to interact with steroid hormone signaling to modulate lifespan. Together with the observation that transplanted ovaries from young donor mice can increase the life expectancy of old recipient mice (Cargill et al., 2003; Mason et al., 2009), these findings suggest that the gonad regulation of lifespan might be evolutionarily conserved. By virtue of functional and sequence homologies in several aspects of endocrine regulation among species we speculate that the mechanisms described in worms and flies might be evolutionarily conserved and thus also play a role in mammals.

\section{Acknowledgements}

We thank the editors of this special issue, Holly Brown-Borg and Kurt Borg, for their invitation to write this review, and Holly BrownBorg for inviting TF to present parts of this paper at the 10th International Symposium on Neurobiology and Neuroendocrinology of Aging in Bregenz, Austria. We also thank Anne Simon, Véronique Monnier, Hervé Tricoire, and Marc Tatar for many stimulating discussions about some of the ideas presented here. Due to space limitations we often had to cite reviews rather than primary references, and we apologize to those colleagues whose work we could not cite. Our work was supported by a grant from the Austrian Science Foundation (FWF) to TF (P21498-B11).

\section{References}

Andres, A.J., Fletcher, J.C., Karim, F.D., Thummel, C.S., 1993. Molecular analysis of the initiation of insect metamorphosis: a comparative study of Drosophila ecdysteroidregulated transcription. Dev. Biol. 160, 388.

Antebi, A., Yeh, W.H., Tait, D., Hedgecock, E.M., Riddle, D.L., 2000. daf-12 encodes a nuclear receptor that regulates the dauer diapause and developmental age in $C$. elegans. Genes Dev. 14, 1512-1527.

Bai, J., Uehara, Y., Montell, D.J., 2000. Regulation of invasive cell behavior by taiman, a Drosophila protein related to AIB1, a steroid receptor coactivator amplified in breast cancer. Cell 103, 1047-1058.

Baker, K.D., Shewchuk, L.M., Kozlova, T., Makishima, M., Hassell, A., Wisely, B., Caravella, J.A., Lambert, M.H., Reinking, J.L., Krause, H., Thummel, C.S., Willson, T.M., Mangelsdorf, D.J., 2003. The Drosophila orphan nuclear receptor DHR38 mediates an atypical ecdysteroid signaling pathway. Cell 113, 731-742.

Bender, M., Imam, F.B., Talbot, W.S., Ganetzky, B., Hogness, D.S., 1997. Drosophila ecdysone receptor mutations reveal functional differences among receptor isoforms. Cell 91, 777.

Bownes, M., 1982. Hormonal and genetic regulation of vitellogenesis in Drosophila. Q. Rev. Biol. 57, 247-274.

Broué, F., Liere, P., Kenyon, C., Baulieu, E.E., 2007. A steroid hormone that extends the lifespan of Caenorhabditis elegans. Aging Cell 6, 87-94.

Buszczak, M., Freeman, M.R., Carlson, J.R., Bender, M., Cooley, L., Segraves, W.A., 1999. Ecdysone response genes govern egg chamber development during mid-oogenesis in Drosophila. Development 126, 4581-4589.

Cargill, S.L., Carey, J.R., Muller, H.-G., Anderson, G., 2003. Age of ovary determines remaining life expectancy in old ovariectomized mice. Aging Cell 2, 185-190.

Carney, G.E., Bender, M., 2000. The Drosophila ecdysone receptor (EcR) gene is required maternally for normal oogenesis. Genetics 154, 1203-1211.

Chawla, A., Repa, J.J., Evans, R.M., Mangelsdorf, D.J., 2001. Nuclear receptors and lipid physiology: opening the X-files. Science 294, 1866-1870.

Colombani, J., Bianchini, L., Layalle, S., Pondeville, E., Dauphin-Villemant, C., Antoniewski, C., Carre, C., Noselli, S., Leopold, P., 2005. Antagonistic actions of ecdysone and insulins determine final size in Drosophila. Science 310,667-670.

Dowell, P., Otto, T.C., Adi, S., Lane, M.D., 2003. Convergence of peroxisome proliferatoractivated receptor gamma and Foxo1 signaling pathways. J. Biol. Chem. 278, 45485-45491.

Dressel, U., Thormeyer, D. Altincicek, B. Paululat, A., Eggert, M. Schneider, S., Tenbaum, S.P., Renkawitz, R., Baniahmad, A., 1999. Alien, a highly conserved protein with characteristics of a corepressor for members of the nuclear hormone receptor superfamily. Mol. Cell. Biol. 19, 3383-3394.

Dumas, K.J., Guo, C., Wang, X., Burkhart, K.B., Adams, E.J., Alam, H., Hu, P.J., 2010 Functional divergence of dafachronic acid pathways in the control of $C$. elegans development and lifespan. Dev. Biol. 340, 605-612.

Fallon, A.M., Gerenday, A., 2010. Ecdysone and the cell cycle: Investigations in a mosquito cell line. J. Insect Physiol. 56, 1396-1401

Fielenbach, N., Antebi, A., 2008. C. elegans dauer formation and the molecular basis of plasticity. Genes Dev. 22, 2149-2165.

Finch, C.E., Rose, M.R., 1995. Hormones and the physiological architecture of life history evolution. Q. Rev. Biol. 70, 1-52.

Fisher, A.L., Lithgow, G.J., 2006. The nuclear hormone receptor DAF-12 has opposing effects on Caenorhabditis elegans lifespan and regulates genes repressed in multiple long-lived worms. Aging Cell 5, 127-138.

Flatt, T., Kawecki, T.J., 2007. Juvenile hormone as a regulator of the trade-off between reproduction and life span in Drosophila melanogaster. Evolution 61, 1980-1991.

Flatt, T., Tu, M.P., Tatar, M., 2005. Hormonal pleiotropy and the juvenile hormone regulation of Drosophila development and life history. Bioessays 27, 999-1010.

Flatt, T., Moroz, L.L., Tatar, M., Heyland, A., 2006. Comparing thyroid and insect hormone signaling. Integr. Comp. Biol. 46, 777-794.

Flatt, T., Min, K.J., D'Alterio, C., Villa-Cuesta, E., Cumbers, J., Lehmann, R., Jones, D.L., Tatar, M., 2008a. Drosophila germ-line modulation of insulin signaling and lifespan. Proc. Natl Acad. Sci. USA 105, 6368-6373.

Flatt, T., Heyland, A., Rus, F., Porpiglia, E., Sherlock, C., Yamamoto, R., Garbuzov, A., Palli, S.R., Tatar, M., Silverman, N., 2008b. Hormonal regulation of the humoral innate immune response in Drosophila melanogaster. J. Exp. Biol. 211, 2712-2724.

Fluegel, M.L., Parker, T.J., Pallanck, L.J., 2006. Mutations of a Drosophila NPC1 gene confer sterol and ecdysone metabolic defects. Genetics 172, 185-196. 
Francis, G.A., Fayard, E., Picard, F., Auwerx, J., 2003. Nuclear receptors and the control of metabolism. Annu. Rev. Physiol. 65, 261-311.

Freeman, M.R., Dobritsa, A., Gaines, P., Segraves, W.A., Carlson, J.R., 1999. The dare gene: steroid hormone production, olfactory behavior, and neural degeneration in Drosophila. Development 126, 4591-4602.

Gems, D., Sutton, A.J., Sundermeyer, M.L., Albert, P.S., King, K.V., Edgley, M.L., Larsen, P.L., Riddle, D.L., 1998. Two pleiotropic classes of daf-2 mutation affect larval arrest, adult behavior, reproduction and longevity in Caenorhabditis elegans. Genetics 150, 129-155.

Gerisch, B., Antebi, A., 2004. Hormonal signals produced by DAF-9/cytochrome P450 regulate $C$. elegans dauer diapause in response to environmental cues. Development $131,1765-1776$.

Gerisch, B., Weitzel, C., Kober-Eisermann, C., Rottiers, V., Antebi, A., 2001. A hormonal signaling pathway influencing $C$. elegans metabolism, reproductive development, and life span. Dev. Cell 1, 841-851.

Gerisch, B., Rottiers, V., Li, D., Motola, D.L., Cummins, C.L., Lehrach, H., Mangelsdorf, D.J., Antebi, A., 2007. A bile acid-like steroid modulates Caenorhabditis elegans lifespan through nuclear receptor signaling. Proc. Natl Acad. Sci. USA 104, 5014-5019.

Giannakou, M.E., Partridge, L., 2007. Role of insulin-like signalling in Drosophila lifespan. Trends Biochem. 32, 180-188.

Gilbert, L.I., Warren, J.T., 2005. A molecular genetic approach to the biosynthesis of the insect steroid molting hormone. Vitam. Horm. 73, 31-57.

Gilbert, L.I., Rybczynski, R., Warren, J.T., 2002. Control and biochemical nature of the ecdysteroidogenic pathway. Annu. Rev. Entomol. 47, 883-916.

Gissendanner, C.R., Crossgrove, K., Kraus, K.A., Maina, C.V., Sluder, A.E., 2004. Expression and function of conserved nuclear receptor genes in Caenorhabditis elegans. Dev. Biol. 266, 399-416.

Gronemeyer, H., Laudet, V., 2001. Nuclear receptor facts book. Academic Press, London.

Held, J.M., White, M.P., Fisher, A.L., Gibson, B.W., Lithgow, G.J., Gill, M.S., 2006. DAF-12dependent rescue of dauer formation in Caenorhabditis elegans by (25S)cholestenoic acid. Aging Cell 5, 283-291.

Honegger, B., Galic, M., Kohler, K., Wittwer, F., Brogiolo, W., Hafen, E., Stocker, H., 2008. Imp-L2, a putative homolog of vertebrate IGF-binding protein 7, counteracts insulin signaling in Drosophila and is essential for starvation resistance. J. Biol. 7, 10.

Horner, M.A., Pardee, K., Liu, S., King-Jones, K., Lajoie, G., Edwards, A., Krause, H.M. Thummel, C.S., 2009. The Drosophila DHR96 nuclear receptor binds cholesterol and regulates cholesterol homeostasis. Genes Dev. 23, 2711-2716.

Hsin, H., Kenyon, C., 1999. Signals from the reproductive system regulate the lifespan of C. elegans. Nature 399, 362-366.

Huang, X., Suyama, K., Buchanan, J., Zhu, A.J., Scott, M.P., 2005. A Drosophila model of the Niemann-Pick type $C$ lysosome storage disease: dnpc1a is required for molting and sterol homeostasis. Development 132, 5115-5124.

Huang, X., Warren, J.T., Buchanan, J., Gilbert, L.I., Scott, M.P., 2007. Drosophila NiemannPick type C-2 genes control sterol homeostasis and steroid biosynthesis: a model of human neurodegenerative disease. Development 134, 3733-3742.

shimoto, H., Sakai, T. Kitamoto, T, 2009. Ecdysone signaling regulates the formation of long-term courtship memory in adult Drosophila melanogaster. Proc. Natl Acad. Sci. USA 106, 6381-6386.

Iia, K., Albert, P.S., Riddle, D.L., 2002. DAF-9, a cytochrome P450 regulating C. elegans larval development and adult longevity. Development 129, 221-231.

King-Jones, K., Thummel, C.S., 2005. Nuclear receptors - a perspective from Drosophila. Nat. Rev. Genet. 6, 311-323.

King-Jones, K., Horner, M.A., Lam, G., Thummel, C.S., 2006. The DHR96 nuclear receptor regulates xenobiotic responses in Drosophila. Cell Metab. 4, 37-48.

Koelle, M.R., Talbot, W.S., Segraves, W.A., Bender, M.T., Cherbas, P., Hogness, D.S., 1991 The Drosophila EcR gene encodes an ecdysone receptor, a new member of the steroid receptor family. Cell 67, 59-77.

Kozlova, T., Thummel, C.S., 2000. Steroid regulation of postembryonic development and reproduction in Drosophila. Trends Endocrinol. Metab. 11, 276-280.

Kurzchalia, T.V., Ward, S., 2003. Why do worms need cholesterol? Nat. Cell Biol. 5, 684-688. L’Allemand, D., Penhoat, A., Lebrethon, M.C., Ardevol, R., Baehre, V., Oelkers, W., Saez, J.M., 1996. Insulin-like growth factors enhance steroidogenic enzyme and corticotropin receptor messenger ribonucleic acid levels and corticotropin steroidogenic responsiveness in cultured human adrenocortical cells. J. Clin. Endocrinol. Metab. 81, 3892-3897.

Larsen, P.L., Albert, P.S., Riddle, D.L., 1995. Genes that regulate both development and longevity in Caenorhabditis elegans. Genetics 139, 1567-1583.

Li, J., Brown, G., Ailion, M., Lee, S., Thomas, J.H., 2004. NCR-1 and NCR-2, the C. elegans homologs of the human Niemann-Pick type C1 disease protein, function upstream of DAF-9 in the dauer formation pathways. Development 131, 5741-5752.

Ludewig, A.H., Kober-Eisermann, C., Weitzel, C., Bethke, A., Neubert, K., Gerisch, B., Hutter, H., Antebi, A., 2004. A novel nuclear receptor/coregulator complex controls C. elegans lipid metabolism, larval development, and aging. Genes Dev. 18, 2120-2133.

Magner, D.B., Antebi, A., 2008. Caenorhabditis elegans nuclear receptors: insights into life traits. Trends Endocrinol. Metab. 19, 153-160.

Mak, H.Y., Ruvkun, G., 2004. Intercellular signaling of reproductive development by the C. elegans DAF-9 cytochrome P450. Development 131, 1777-1786.

Mangelsdorf, D.J., Evans, R.M., 1995. The RXR heterodimers and orphan receptors. Cell $83,841$.

Maniere, G., Rondot, I., Bullesbach, E.E., Gautron, F., Vanhems, E., Delbecque, J.P., 2004 Control of ovarian steroidogenesis by insulin-like peptides in the blowfly (Phormia regina). J. Endocrinol. 181, 147-156.

Mason, J.B., Cargill, S.L., Anderson, G.B., Carey, J.R., 2009. Transplantation of young ovaries to old mice increased life span in transplant recipients. J. Gerontol. A Biol. Sci. Med. Sci. 64, 1207-1211.
Matyash, V., Entchev, E.V., Mende, F., Wilsch-Brauninger, M., Thiele, C., Schmidt, A.W., Knolker, H.J., Ward, S., Kurzchalia, T.V., 2004. Sterol-derived hormone(s) controls entry into diapause in Caenorhabditis elegans by consecutive activation of DAF-12 and DAF-16. PLoS Biol. 2, 1561-1571.

McBrayer, Z., Ono, H., Shimell, M., Parvy, J.P., Beckstead, R.B., Warren, J.T., Thummel, C.S., Dauphin-Villemant, C., Gilbert, L.I., O'Connor, M.B., 2007. Prothoracicotropic hormone regulates developmental timing and body size in Drosophila. Dev. Cell $13,857-871$.

McCulloch, D., Gems, D., 2007. Sex-specific effects of the DAF-12 steroid receptor on aging in Caenorhabditis elegans. Ann. NY Acad. Sci. 1119, 253-259.

Motola, D.L., Cummins, C.L., Rottiers, V., Sharma, K.K., Li, T., Li, Y., Suino-Powell, K., Xu, H.E., Auchus, R.J., Antebi, A., Mangelsdorf, D.J., 2006. Identification of ligands for DAF-12 that govern dauer formation and reproduction in C. elegans. Cell 124, 1209-1223.

Mouillet, J.F., Henrich, V.C., Lezzi, M., Vogtli, M., 2001. Differential control of gene activity by isoforms A, B1 and B2 of the Drosophila ecdysone receptor. Eur. J. Biochem. 268, 1811-1819.

Natzle, J.E., Hammonds, A.S., Fristrom, J.W., 1986. Isolation of genes active during hormone-induced morphogenesis in Drosophila imaginal discs. J. Biol. Chem. 261, $5575-5583$

Oliver, B., Perrimon, N., Mahowald, A.P., 1987. The ovo locus is required for sex-specific germ line maintenance in Drosophila. Genes Dev. 1, 913-923.

Osterbur, D.L., Fristrom, D.K., Natzle, J.E., Tojo, S.J., Fristrom, J.W., 1988. Genes expressed during imaginal discs morphogenesis: IMP-L2, a gene expressed during imaginal disc and imaginal histoblast morphogenesis. Dev. Biol. 129, 439-448.

Patel, D.S., Fang, L.L., Svy, D.K., Ruvkun, G., Li, W., 2008. Genetic identification of HSD-1, a conserved steroidogenic enzyme that directs larval development in Caenorhabditis elegans. Development 135, 2239-2249.

Petryk, A., Warren, J.T., Marques, G., Jarcho, M.P., Gilbert, L.I., Kahler, J., Parvy, J.P., Li, Y., Dauphin-Villemant, C., O'Connor, M.B., 2003. Shade is the Drosophila P450 enzyme that mediates the hydroxylation of ecdysone to the steroid insect molting hormone 20-hydroxyecdysone. Proc. Natl Acad. Sci. USA 100, 13773-13778.

Richard, D.S., Watkins, N.L., Serafin, R.B., Gilbert, L.I., 1998. Ecdysteroids regulate yolk protein uptake by Drosophila melanogaster oocytes. J. Insect Physiol. 44,637-644.

Richard, D.S., Gilbert, M., Crum, B., Hollinshead, D.M., Schelble, S., Scheswohl, D., 2001. Yolk protein endocytosis by oocytes in Drosophila melanogaster: immunofluorescent localization of clathrin, adaptin and the yolk protein receptor. J. Insect Physiol. 47, 715-723.

Riddiford, L.M., 1993. Hormones and Drosophila development. In: Bate, M., Martinez Arias, A. (Eds.), The development of Drosophila melanogaster. Cold Spring Harbor Laboratory Press, Cold Spring Harbor.

Riddiford, L.M., Cherbas, P., Truman, J.W., 2000. Ecdysone receptors and their biological actions. Vitamins \& Hormones. Academic Press.

Riddle, D.L., Swanson, M.M., Albert, P.S., 1981. Interacting genes in nematode dauer larva formation. Nature 290, 668-671

Riehle, M.A., Brown, M.R., 1999. Insulin stimulates ecdysteroid production through a conserved signaling cascade in the mosquito Aedes aegypti. Insect Biochem. Mol. Biol. 29, 855.

Robinson-Rechavi, M., Maina, C.V., Gissendanner, C.R., Laudet, V., Sluder, A., 2005. Explosive lineage-specific expansion of the orphan nuclear receptor HNF4 in nematodes. J. Mol. Evol. 60, 577-586.

Romani, P., Bernardi, F., Hackney, J., Dobens, L., Gargiulo, G., Cavaliere, V., 2009. Cell survival and polarity of Drosophila follicle cells require the activity of ecdysone receptor B1 isoform. Genetics 181, 165-175.

Rottiers, V., Antebi, A., 2006. Control of Caenorhabditis elegans life history by nuclear receptor signal transduction. Exp. Gerontol. 41, 904-909.

Rottiers, V., Motola, D.L., Gerisch, B., Cummins, C.L., Nishiwaki, K., Mangelsdorf, D.J. Antebi, A., 2006. Hormonal control of C. elegans dauer formation and life span by a Rieske-like oxygenase. Dev. Cell 10, 473-482.

Russell, S.J., Kahn, C.R., 2007. Endocrine regulation of ageing. Nat. Rev. Mol. Cell Biol. 8, 681-691.

Schmidt, P.S., Paaby, A.B., 2008. Reproductive diapause and life-history clines in North American populations of Drosophila melanogaster. Evolution 62, 1204-1215.

Schmidt, P.S., Zhu, C.T., Das, J., Batavia, M., Yang, L., Eanes, W.F., 2008. An amino acid polymorphism in the couch potato gene forms the basis for climatic adaptation in Drosophila melanogaster. Proc. Natl Acad. Sci. USA 105, 16207-16211.

Sharma, K.K. Wang Z Motola, D.L. Cummins, C.L. Mangelsdorf, D.J., Auchus, R.J., 2009. Synthesis and activity of dafachronic acid ligands for the $C$. elegans DAF-12 nuclear hormone receptor. Mol. Endocrinol. 23, 640-648.

Simon, A.F., Krantz, D.E., 2005. Dissociation between extension of longevity and resistance to stress in alleles of the steroid biosynthesis gene dare. Ann. Dros. Res. Conf. 46 (Suppl. 1021A)

Simon, A.F., Shih, C., Mack, A., Benzer, S., 2003. Steroid control of longevity in Drosophila melanogaster. Science 299, 1407-1410.

Snow, M.I., Larsen, P.L., 2000. Structure and expression of daf-12: a nuclear hormone receptor with three isoforms that are involved in development and aging in Caenorhabditis elegans. Biochim. Biophys. Acta 1494, 104-116.

Spindler, K.D., Honl, C., Tremmel, C., Braun, S., Ruff, H., Spindler-Barth, M., 2009. Ecdysteroid hormone action. Cell. Mol. Life Sci. 66, 3837-3850.

Srivastava, D.P., Yu, E.J., Kennedy, K., Chatwin, H., Reale, V., Hamon, M., Smith, T., Evans, P.D., 2005. Rapid, nongenomic responses to ecdysteroids and catecholamines mediated by a novel Drosophila G-protein-coupled receptor. J. Neurosci. 25, $6145-6155$

Sym, M., Basson, M., Johnson, C., 2000. A model for Niemann-Pick type C disease in the nematode Caenorhabditis elegans. Curr. Biol. 10, 527-530.

Tatar, M., Yin, C.M., 2001. Slow aging during insect reproductive diapause: why butterflies, grasshoppers and flies are like worms. Exp. Gerontol. 36, 723-738. 
Tatar, M., Bartke, A., Antebi, A., 2003. The endocrine regulation of aging by insulin-like signals. Science 299, 1346-1351.

Thomas, J.H., Birnby, D.A., Vowels, J.J., 1993. Evidence for parallel processing of sensory information controlling dauer formation in Caenorhabditis elegans. Genetics 134 $1105-1117$.

Thummel, C.S., 1996. Flies on steroids: Drosophila metamorphosis and the mechanisms of steroid hormone action. Trends Genet. 12, 306-310.

Thummel, C.S., 2001a. Molecular mechanisms of developmental timing in C. elegans and Drosophila. Dev. Cell 1, 453-465.

Thummel, C.S., 2001b. Steroid-triggered death by autophagy. Bioessays 23, 677-682.

Toivonen, J.M., Partridge, L., 2009. Endocrine regulation of aging and reproduction in Drosophila. Mol. Cell. Endocrinol. 299, 39-50.

Tricoire, H., Battisti, V., Trannoy, S., Lasbleiz, C., Pret, A.M., Monnier, V., 2009. The steroid hormone receptor EcR finely modulates Drosophila lifespan during adulthood in a sex-specific manner. Mech. Ageing Dev. 130, 547-552.

Truman, J.W., 2005. Hormonal control of insect ecdysis: endocrine cascades for coordinating behavior with physiology. Vitam. Horm. 73, 1-30.

Tsai, C.-C., Kao, H.-Y., Yao, T.-P., McKeown, M., Evans, R.M., 1999. SMRTER, a Drosophila nuclear receptor coregulator, reveals that EcR-mediated repression is critical for development. Mol. Cell 4, 175.

Tu, M.P., Yin, C.M., Tatar, M., 2002. Impaired ovarian ecdysone synthesis of Drosophila melanogaster insulin receptor mutants. Aging Cell 1,158-160.
Tu, M.P., Flatt, T., Tatar, M., 2006. Juvenile and steroid hormones in Drosophila melanogaster longevity. Chapter 16, In: Masoro, Edward J., Austad, Steven N. (Eds.), Handbook of the Biology of Aging, 6th ed. Academic Press (Elsevier), San Diego, pp. 415-448.

Vowels, J.J., Thomas, J.H., 1992. Genetic analysis of chemosensory control of dauer formation in Caenorhabditis elegans. Genetics 130, 105-123.

Walker, V.K., Watson, K.L., Holden, J.A., Steel, C.G.H., 1987. Vitellogenesis and fertility in Drosophila females with low ecdysteroid titres; the L(3)3 DTS mutation. J. Insect Physiol. 33, 137-142.

Walkiewicz, M.A., Stern, M., 2009. Increased insulin/insulin growth factor signaling advances the onset of metamorphosis in Drosophila. PLoS ONE 4, e5072.

Yamawaki, T.M., Arantes-Oliveira, N., Berman, J.R., Zhang, P., Kenyon, C., 2008. Distinct activities of the germline and somatic reproductive tissues in the regulation of Caenorhabditis elegans' longevity. Genetics 178, 513-526.

Yao, T.P., Forman, B.M., Jiang, Z., Cherbas, L., Chen, J.D., McKeown, M., Cherbas, P., Evans, R.M., 1993. Functional ecdysone receptor is the product of EcR and ultraspiracle genes. Nature 366, 476.

Yoshiyama, T. Namiki, T., Mita, K. Kataoka, H., Niwa, R., 2006. Neverland is an evolutionally conserved Rieske-domain protein that is essential for ecdysone synthesis and insect growth. Development 133, 2565-2574. 